CASE REPORT

\title{
Cryptococcal Cellulitis in a Diabetic with Nephropathy on Adalimumab Therapy for Rheumatoid Arthritis
}

\author{
Christine A. Moore, Imranali Khan, Almira Opardija, Parasbhai D. Patel \\ Department of Internal Medicine, East Tennessee State University, James H. Quillen College of Medicine, Johnson \\ City, TN, USA
}

\begin{abstract}
Cutaneous infection with Cryptococcus neoformans is rare but can occur in the setting of rheumatoid arthritis due to immunosuppression. Risk factors include chronic kidney disease and use of tumor necrosis factor-alpha (TNF- $\alpha$ ) inhibitor adalimumab. We report the fourth case of primary cutaneous cryptococcosis (PCC) in a diabetic female more than 60 years old living in rural Northwest Tennessee and taking adalimumab for rheumatoid arthritis. In a literature review of existing cases, this is the second case involving simultaneous chronic kidney disease and the first case in a diabetic and following extended TNF- $\alpha$ inhibitor immunosuppression monotherapy. Physicians should consider cryptococcal infection in a patient who develops cellulitis that is unresponsive to empiric therapy. In addition, it is imperative to monitor rheumatoid arthritis patients taking adalimumab closely and consider alternative agents in those with pre-existing immunosuppression or known risk factors for opportunistic infections as primary prevention. $J$ Microbiol Infect Dis 2017; 7(3):160-163
\end{abstract}

Keywords: Cryptococcus neoformans, rheumatoid arthritis, adalimumab, diabetes mellitus, chronic kidney disease

\section{INTRODUCTION}

Cryptococcus neoformans is an opportunistic fungal pathogen that infects the lung, central nervous system, and skin [1]. Primary cutaneous cryptococcosis (PCC) including cellulitis is rare and more common in patients with immunosuppression such as rheumatoid arthritis [2]. Infection risk factors specific to rheumatoid arthritis are chronic kidney disease and use of tumor necrosis factor-alpha (TNF- $\alpha$ ) inhibitor adalimumab [3]. Three previous cases of PCC involving rheumatoid arthritis patients taking adalimumab occurred in the setting of short-term (<12 months) TNF- $\alpha$ use and concurrent immunosuppressive therapy [4-6]. We report a case of cryptococcal cellulitis in a diabetic female older than 60 years with chronic kidney disease who was treated with long-term ( $>24$ months) adalimumab monotherapy for rheumatoid arthritis.

\section{CASE}

A 66 year-old diabetic female with rheumatoid arthritis treated with adalimumab for two years was admitted with right upper extremity (RUE) cellulitis. She used to smoke 1 pack a day for 15 years but never drank alcohol or used illicit drugs, and lived on rural Northwest Tennessee property in a trailer with her husband and their dog.

One month before admission, she bumped her elbow inside the trailer and developed a lump draining purulent material; she applied rubbing alcohol and let her dog lick it occasionally. The week prior to presentation, she was cleaning her trailer and handling fiberglass without gloves. She awoke from sleep that evening with sharp pain and pruritis in her RUE, similar to a mosquito bite. Topical diphenhydramine brought no relief then she noticed redness and swelling the next morning and went to the emergency room. She tried oral clindamycin without improvement and returned to the hospital. Doppler U/S of RUE was negative for deep vein thrombosis, CT revealed extensive subcutaneous edema with fluid within the dorsal and ulnar aspects of the proximal and midforearm but no focal abscess. The orthopedic

Correspondence: Dr. Christine Moore, 1185 West Mountain View Road, Apartment 1509, Johnson City, TN, USA,

E-mail: mooreca2@etsu.edu

Received: 24 January 2017 Accepted: 21 June 2017

Copyright (C) JMID / Journal of Microbiology and Infectious Diseases 2017, All rights reserved 
surgeon recommended medical management with intravenous antibiotics. She was admitted for additional work-up and started on intravenous piperacillin-tazobactam and hydromorphone. Despite therapy, her RUE pain and swelling did not improve and she developed oozing blisters accompanied by anorexia, weakness and high fevers. One out of two blood cultures grew gram-positive cocci. She was transferred to our service for infectious disease consult regarding treatment of cellulitis.

On admission, her temperature was $39.2 \mathrm{0C}$, heart rate 115 /minute, respirations 26 /minute, and blood pressure $133 / 70 \mathrm{mmHg}$. The patient was obese. Erythema and superficial desquamation covered her right posterior forearm and an extremely tender necrotic eschar encompassed her right anterior forearm (Figure 1). Bilateral finger deformities secondary to rheumatoid arthritis were noted. Remainder of exam was unremarkable. White blood cell count was $11.5 \mathrm{~K} / \mu \mathrm{L} \quad(3.5-10.5 \mathrm{~K} / \mu \mathrm{L})$ with $78 \%$ polymorphonuclear leukocytes (45-75\%), hemoglobin $10.6 \mathrm{~g} / \mathrm{dL} \quad(12.4-15.2 \mathrm{~g} / \mathrm{dL})$, hematocrit $32.2 \% \quad(36.0-46.0 \%)$, and mean corpuscular volume $86.5 \mathrm{fL}(80.0-100.0 \mathrm{fL})$. Complete metabolic profile revealed sodium 134 $\mathrm{mmol} / \mathrm{L}$ (136-145 $\mathrm{mmol} / \mathrm{L})$, carbon dioxide 21 $\mathrm{mmol} / \mathrm{L}$ (22-32 $\mathrm{mmol} / \mathrm{L})$, anion gap $16 \mathrm{mmol} / \mathrm{L}$ (5-15 mmol/L), blood urea nitrogen $9 \mathrm{mg} / \mathrm{dL}(6$ $20 \mathrm{mg} / \mathrm{dL})$, creatinine $1.30 \mathrm{mg} / \mathrm{dL}(0.60-1.10$ $\mathrm{mg} / \mathrm{dL}$ ), estimated glomerular filtration rate 44 $\mathrm{mL} / \mathrm{min} / \mathrm{SA}$ (>60 $\mathrm{ml} / \mathrm{min} / \mathrm{SA}$ ), and calcium 7.3 $\mathrm{mg} / \mathrm{dL}$ (8.6-10.0 $\mathrm{mg} / \mathrm{dL})$; magnesium was 1.4 $\mathrm{mg} / \mathrm{dL}(1.6-2.6 \mathrm{mg} / \mathrm{dL})$.

The primary team replaced magnesium then began intravenous daptomycin and tobramycin. Infectious disease changed daptomycin to ceftriaxone and added clindamycin. Repeat blood cultures were negative. Orthopedic surgery performed incision and debridement of right upper extremity. Intraoperative wound cultures grew Cryptococcus neoformans and Bacillus cereus, the latter proved to be a contaminant. Serum cryptococcal antigen was negative. Antibacterials were discontinued and started intravenous fluconazole $400 \mathrm{mg}$. Skin symptoms markedly improved. She was discharged to short-term rehabilitation center for wound care for RUE with oral fluconazole 200 $\mathrm{mg}$ for twelve months and permanent cessation of adalimumab.

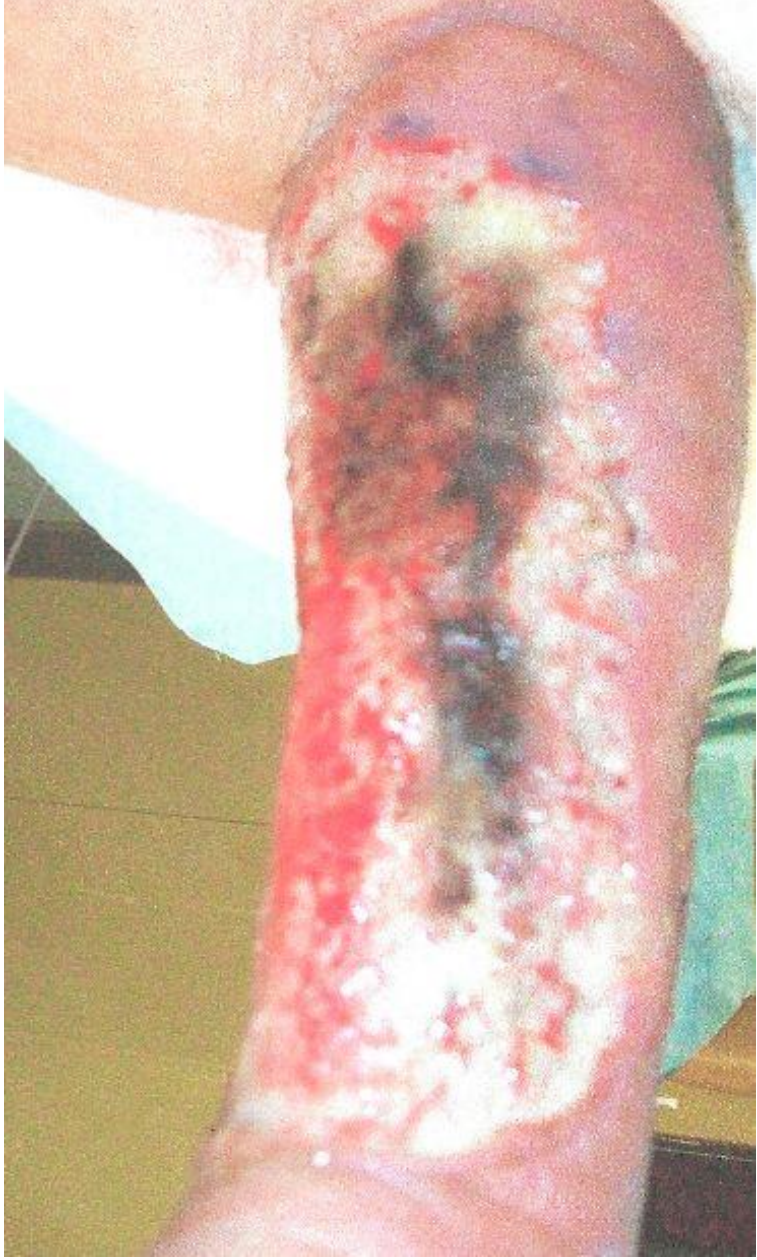

Figure 1. Right forearm, anterior.

\section{DISCUSSION}

Cryptococcus neoformans, the most common Cryptococcus species, is a yeast-like encapsulated fungus associated with the droppings of pigeons [7]. When inhaled, it can cause pulmonary infections such as pneumonia. In immunocompromised patients, it can spread to the central nervous system (CNS) and skin in disseminated disease. Cutaneous infections are rare, occur more frequently in immunocompromised patients, and include the classic whitlow or phlegmon (pedunculated, dome-shaped papule with an umbilicated center), cellulitis, necrotizing fasciitis, and cryptococcomas [8]. Primary cutaneous cryptococcosis (PCC) is defined as localized skin lesion(s), positive tissue culture, and lack of evidence of systemic disease [9]. Diagnose PCC with skin biopsy and/or culture [9]. Other labs include latex agglutination and cryptococcal antigen to rule out disseminated infection and 
determine the need for lumbar puncture. Treatment of PCC includes fluconazole for $6-12$ months; other options are itraconazole, voriconazole, posaconazole, and amphotericin $\mathrm{B}$ [10]. If the patient fails to heal or cannot tolerate medical therapy, surgery is recommended.

There are several reports of invasive cryptococcal infection including PCC in patients with rheumatoid arthritis. In fact, it can mimic cutaneous vasculitis; however, this is more frequent on the lower extremities [2]. Patients with rheumatoid arthritis have immunosuppression from treatment: high-dose glucocorticoids, disease-modifying antirheumatic drugs (DMARDs), and biologics. Risk factors for cryptococcal infection in rheumatoid arthritis include chronic kidney disease and use of adalimumab (adjusted odds ratios 2.72 and 4.50, respectively) [3].

Adalimumab (Humira ${ }^{\circledR}$ ), a monoclonal antibody against tumor necrosis factor alpha (TNF- $\alpha$ ), is a biologic used in the treatment of rheumatoid arthritis. TNF- $\alpha$ is a cytokine released by the protective T-cells and activates monocytes to differentiate into macrophages that recruit others to engulf fungi such as Cryptococcus through phagocytosis. Patients who are taking TNF- $\alpha$ inhibitors such as adaliumumab have decreased macrophage function and increased susceptibility to opportunistic infection [11]. While there were no reports of cryptococcal infections in the post-marketing database, there have been multiple cases documented in the literature since then [12]. Adalimumab has increased cytokine binding avidity, slower dissociation, and longer half-life compared to other TNF- $\alpha$ inhibitors, increasing its propensity to compromise immunity. If an opportunistic infection is suspected, it is necessary to discontinue adalimumab to allow immune system recuperation and prevent further damage.

There are several reports of primary PCC in rheumatoid arthritis patients receiving adalimumab [4-6]. We have summarized these cases in the table 1 (Table 1 ).

Table 1. Summary of reported cases of primary cutaneous cryptococcosis in the setting of rheumatoid arthritis on adalimumab therapy

\begin{tabular}{|c|c|c|c|c|c|c|c|}
\hline $\begin{array}{l}\text { Study } \\
\text { (year) }\end{array}$ & $\begin{array}{l}\text { Gender } \\
\text { (years) }\end{array}$ & Location & Exposures & $\begin{array}{c}\text { Adalimumab } \\
\text { use } \\
\text { (months) }\end{array}$ & $\begin{array}{c}\text { Other } \\
\text { immunosuppression }\end{array}$ & $\begin{array}{c}\text { Co- } \\
\text { morbidities }\end{array}$ & $\begin{array}{c}\text { Clinical course } \\
\text { (weeks) }\end{array}$ \\
\hline $\begin{array}{l}\text { Horcajada } \\
\text { et al } \\
(2007)\end{array}$ & $\begin{array}{c}\text { Female } \\
(69)\end{array}$ & $\begin{array}{l}\text { 2nd left } \\
\text { finger }\end{array}$ & None & 12 & $\begin{array}{l}\text { Prednisone, } \\
\text { methotrexate, } \\
\text { chloroquine, } \\
\text { sulfasalazine }\end{array}$ & $\begin{array}{l}\text { Age }>60 \\
\text { years }\end{array}$ & $\begin{array}{c}\text { Liposomal } \\
\text { amphotericin B + } \\
\text { flucytosine (1), } \\
\text { fluconazole (3), } \\
\text { 2nd digit } \\
\text { amputation, } \\
\text { fluconazole (24) }\end{array}$ \\
\hline $\begin{array}{l}\text { Wilson et } \\
\text { al (2008) }\end{array}$ & $\begin{array}{c}\text { Female } \\
(58)\end{array}$ & $\begin{array}{c}\text { 2nd right } \\
\text { proximal } \\
\text { inter- } \\
\text { phalangeal } \\
\text { joint }\end{array}$ & $\begin{array}{l}\text { Splinter } \\
\text { from wood } \\
\text { board }\end{array}$ & $\begin{array}{l}0 \text { (started at } \\
\text { the time of } \\
\text { infection) }\end{array}$ & $\begin{array}{c}\text { Methotrexate, } \\
\text { hydroxychloroquine }\end{array}$ & None & Fluconazole (24) \\
\hline
\end{tabular}

\begin{tabular}{|c|c|c|c|c|c|c|}
\hline $\begin{array}{l}\text { Gomes et } \\
\text { al (2013) }\end{array}$ & $\begin{array}{c}\text { Male } \\
(87)\end{array}$ & Left hand & None & $\begin{array}{l}<12 \text { (exact } \\
\text { duration } \\
\text { unknown) }\end{array}$ & Prednisone & $\begin{array}{cc}\text { Age }>60 & \text { Fluconazole }(24) \\
\text { years, chronic } & \text { cryptococcoma } \\
\text { kidney } & \text { excision, } \\
\text { disease } & \text { fluconazole }(24)\end{array}$ \\
\hline
\end{tabular}

Our patient was diabetic with both risk factors mentioned earlier for invasive cryptococcal infection. Unlike other reports, she had been taking adalimumab for two years with no additional therapy. Diabetes mellitus and age greater than 60 years both contributed to her immunocompromised state and increased her susceptibility for opportunistic infection [13]. Her exposure to Cryptococcus likely came from the 
rural Northwest Tennessee environment and her dog. Neuville et al found that patients with PCC were more likely to live in rural areas than patients with cutaneous cryptococcosis secondary to hematogenous dissemination [9]. Cryptococcus is uncommonly found in decaying wood, fruits, vegetables, hay and dust in addition to pigeons [14]. Animals including pets and livestock are implicated in fungal dermatophytoses [15].

We present this case of PCC in a patient on adalimumab for rheumatoid arthritis to emphasize the multiple risks for opportunistic infections. Physicians should consider Cryptococcus in the differential for patients who present with cellulitis refractory to empiric therapy. In addition, we reinforce the need for long-term surveillance in rheumatoid arthritis patients on chronic adalimumab and question its use drugs in individuals with pre-existing immunosuppression including diabetes mellitus, greater than 60 years old, and known risk factors for opportunistic infections such as chronic kidney disease.

\section{ACKNOWLEDGMENTS}

\section{Declaration of conflicting interests}

The authors declare that they have no conflict of interest.

\section{Financial disclosure}

No financial support was received.

\section{REFERENCES}

1. Eisenman HC, Casadevall A, McClelland EE. New insights on the pathogenesis of invasive Cryptococcus neoformans infection. Curr Infect Dis Rep 2007;9:457-464.

2. Scott DG, Bacon PA, Tribe CR. Systemic rheumatoid vasculitis: a clinical and laboratory study of 50 cases. Medicine 1981; 60:288-297.

3. Liao TL, Chen YM, Chen DY. Risk factors for cryptococcal infection among patients with rheumatoid arthritis receiving different immunosuppressive medications. Clin Microbiol Infect 2016; 22: 815.e1-815.e3.

4. Gomes RM, Cerio DR, Loghmanee C, et al. Cutaneous cryptococcoma in a patient on TNF-a inhibition. J Clin Med 2013;2:260-263.

5. Horcajada JP, Pena JL, Martinez-Taboada VM, et al. Invasive cryptococcosis and adalimumab treatment. Emerg Infect Dis 2007; 13:953-955.
6. Wilson ML, Sewell LD, Mowad CM. Primary cutaneous cryptococcosis during therapy with methotrexate and adalimumab. J Drugs Derm 2008; 7:53-54

7. Haag-Wackernagel D, Moch $\mathrm{H}$. Health hazards posed by feral pigeons. J Infect 2004; 48:307-313.

8. Aruch DB, Bhusal Y, Hamill RJ. Unusual cause of cellulitis in a patient with hepatitis $C$ and cirrhosis. Am J Med 2011;124: e7-e8.

9. Neuville S, et al. Primary cutaneous cryptococcosis: a distinct clinical entity. Clin Infect Dis 2003; 36:337-347.

10. Perfect J, et al. Clinical practice guidelines for the management of cryptococcal disease: 2010 update by the Infectious Diseases Society of America. Clin Infect Dis 2010; 50:291-322.

11. Koo S, Marty FM, Baden LR. Infectious complications associated with immunomodulating biologic agents. Infect Dis Clin North Am. 2010;24:285-306.

12. Schiff MH, Burmester GR, Kent JD, et al. Safety analysis of adalimumab (Humira) in global clinical trials and US postmarketing surveillance of patients with rheumatoid arthritis. Ann Rheum Dis 2006; 65:889-894.

13. De Marie S. Diseases and drug-related interventions affecting host defence. Eur $\mathrm{J}$ Clin Microbiol Infect Dis 1993; 12:S36.

14. Lazera MS, Cavalcanti MA, Trilles L, et al. Cryptococcus neoformans var. gattii - evidence for a natural habitat related to decaying wood in a pottery tree hollow. Med Mycol 1998; 36:119-22.

15. Nenoff P, Handrick W, Krüger $C$, et al. Dermatomycoses due to pets and farm animals: neglected infections?. Hautarzt 2012; 63:848-858. 